This document is confidential and is proprietary to the American Chemical Society and its authors. Do not copy or disclose without written permission. If you have received this item in error, notify the sender and delete all copies.

\title{
Nanoscale enzymatic compartments in tandem support cascade reactions in vitro
}

\begin{tabular}{|r|l|}
\hline Journal: & Biomacromolecules \\
\hline Manuscript ID & bm-2018-01019w.R1 \\
\hline Manuscript Type: & Article \\
\hline Complete List of Authors: & $\begin{array}{l}\text { Belluati, Andrea; Universitat Basel, Departement Chemie } \\
\text { Craciun, Ioana; Universitat Basel, Departement Chemie } \\
\text { Liu, Juan; University of Basel } \\
\text { Palivan, Cornelia; University of Basel, Chemistry Department }\end{array}$ \\
\hline
\end{tabular}

\section{SCHOLARONE $^{\text {m }}$ \\ Manuscripts}




\section{Nanoscale enzymatic compartments in tandem}

\section{2 support cascade reactions in vitro}

3 Andrea Belluati ${ }^{1}$, Ioana Craciun ${ }^{1}$, Juan Liu' ${ }^{1}$, Cornelia G. Palivan ${ }^{1} *$

$4 \quad{ }^{1}$ Department of Chemistry, University of Basel, Mattenstrasse 24a, CH-4058 Basel

5

$6 \quad$ KEYWORDS

7 Catalytic compartment, polymersome, cascade reaction, in vitro, gout

9 ABSTRACT

10 Compartmentalization at the nanoscale is fundamental in nature, where the spatial segregation of

11 biochemical reactions within cells ensures optimal conditions for regulating metabolic pathways.

12 Here, we present a nature inspired approach to engineer enzymatic cascade reactions taking place

13 between separate vesicular nanocompartments (polymersomes), each containing one enzyme

14 type. We propose by the selected combination of enzymes, an efficient solution to detoxify the

15 harmful effect of uric acid and prevent the accumulation of the derived $\mathrm{H}_{2} \mathrm{O}_{2}$, both being

16 associated with various pathological conditions (e.g. gout and oxidative stress). Fungal uricase

17 and horseradish peroxidase combined to act in tandem, were separately encapsulated within

18 nanocompartments, equipped with channel porins as gates to allow passage of substrates and

19 products from each step of the reaction. We established the molecular factors affecting the

20 efficiency of the overall reaction, and the protective role of the compartments. Interestingly, the 
21 cascade reaction between separate nanocompartments was as efficient as for free enzymes in

22 complex media, such as human serum. The nanocompartments were non-toxic towards cells and

23 more importantly, addition of the tandem catalytic nanocompartments to cells exposed to uric

24 acid provided simultaneous detoxification of uric acid and the $\mathrm{H}_{2} \mathrm{O}_{2}$. Such catalytic

25 nanocompartments can be used as a platform for understanding fundamental factors affecting

26 intra-cellular communication and introduce non-native metabolic reactions into living systems

27 for therapeutic applications.

\section{Introduction}

30 In nature, various enzymatic reactions occur in confined environments where substrates are

31 channeled in between enzymes, or signaling molecules are released and travel between

32 compartments ${ }^{1}$ serving to isolate reactive intermediates, concentrate substrates in a specific

33 region or fine tune reaction pathways. ${ }^{2}$ Inspired by nature, significant efforts have been made to

34 confine enzymes within nanocompartments, such as protein cages, lipid/polymer based

35 compartments and layer by layer capsules, resulting in enzymatic compartments. ${ }^{1,-4}$ Enzymatic

36 compartments are of particular interest as they offer a protective environment that increases the

37 life-time of the encapsulated enzymes, essential for applications. ${ }^{5-6}$ In this respect, a particularly

38 appealing class of compartments are polymersomes generated by self-assembly of amphiphilic

39 copolymers, as their membrane is more stable than the lipid membrane of liposomes, while

40 maintaining biocompatibility if the chemical nature of the copolymer is appropriately selected. ${ }^{7}$

41 A key aspect to allow the enzymatic reaction to take place in situ, inside the cavity of

42 polymersomes, is to render their membrane permeable thus enabling an exchange of substrates 
43 and products with their surroundings. Various approaches have been reported: i) using inherently 44 porous polymersomes, ${ }^{8-9}$ ii) using an external stimulus, such as $\mathrm{pH}$, or by addition of a chemical 45 agent to render the membrane permeable, ${ }^{10-11}$ and iii) inserting biopores or membrane proteins in 46 the membrane. ${ }^{12-13}$

47 Cascade reactions reported within nanocompartments mainly involve encapsulation of one type 48 of enzyme and providing the second enzyme free in the surrounding medium. ${ }^{6,14}$ However, if 49 one partner of the cascade reaction is free in solution it might be degraded, resulting in a 50 decrease or even termination of the overall reaction. Co-encapsulating enzymes within the same 51 nanocompartment solves this issue, but only a low co-encapsulation efficiency can be obtained 52 due to the statistic process of formation of multi-enzyme-loaded polymersomes. ${ }^{7}$

53 A higher encapsulation efficiency of different enzymes can be achieved by linking the two 54 enzymes together prior to encapsulation, using micrometer-sized compartments or the formation 55 of compartments within compartments where small compartments and free enzymes are 56 encapsulated inside micrometer-size compartments. ${ }^{9,}$ 15-18 Both binding the enzymes in one 57 complex and the approach of compartments within compartments, which uses organic solvents 58 and emulsions, have the disadvantage of hindering the catalytic activity of the enzymes thus 59 decreasing the efficiency or blocking the reaction.

60 One approach, which allows for modularity while preserving the enzymes involved in the 61 cascade reaction, is to design catalytic compartments working in tandem. ${ }^{7}$ However, there are 62 only very few examples of catalytic nanocompartments (CNCs) working in tandem ${ }^{8,10,19-20}$ and, 63 to the best of our knowledge, very few polymeric nanocompartments were evaluated in a more 64 complex medium or in vitro. ${ }^{21}$ In addition, the kinetics of the cascade reactions in separate 65 compartments and the molecular factors affecting them were not investigated to determine 
66 whether such CNCs still function in a more complex medium than buffers or to propose a

67 therapeutically relevant solution.

68 Here, we present a bio-inspired approach to engineer CNCs working in tandem and propose, by 69 an appropriate selection of the enzymes, an efficient solution to detoxify the harmful effect of 70 uric acid and $\mathrm{H}_{2} \mathrm{O}_{2}$, associated with various pathologic conditions (e.g. gout and oxidative 71 stress). Both gout and oxidative stress are known to induce severe health problems, associated 72 with an increase in medical costs estimated to be above $\$ 6$ billion per year in the US. ${ }^{22}$ We used 73 an amphiphilic block copolymer poly(2-methyloxazoline)-block-poly(dimethylsiloxane)-block74 poly(2-methyloxazoline) $\left(\mathrm{PMOXA}_{6}-\mathrm{PDMS}_{44}-\mathrm{PMOXA}_{6}\right)$ for the formation of the 75 nanocompartments, ${ }^{23}$ and their membrane was rendered permeable by insertion of the bacterial 76 porin Outer membrane protein $\mathrm{F}(\mathrm{OmpF}){ }^{24}$ The role of the polymersomes is to protect the 77 encapsulated enzymes in order to prolong their stability, as a crucial step towards translational 78 applications, as is intended by our selected enzymatic reaction. We selected as enzymes for the 79 cascade reaction uricase (UOX) and horseradish peroxidase (HRP), which uses $\mathrm{H}_{2} \mathrm{O}_{2}$ produced 80 by UOX, as the substrate to initiate the second reaction (Scheme 1). ${ }^{25-27}$ This non-native 81 combination of enzymes serves to sequentially decrease the concentration of uric acid and 82 prevent the accumulation of $\mathrm{H}_{2} \mathrm{O}_{2}$, derived from the reaction of uric acid degradation, thus 83 resulting in a dual therapeutic approach. While previous reports on cascade reactions between 84 nanocompartments focused on the feasibility of model reactions, ${ }^{20}$ here we go one step further to 85 understand the molecular factors associated with the cascade reaction between separate 86 compartments and to optimize their overall function. Next, we investigate their ability to 87 function at increasing distances to mimic intra- and intercellular bio-distances as well as in 88 human serum, prior to applying them to decrease uric acid and the accumulation of $\mathrm{H}_{2} \mathrm{O}_{2}$, from 
89 the cellular milieu to advance their therapeutic application. Our approach opens the avenue to

90 combine different enzymes inside separate nanocompartments to obtain complex, novel-to-

91 nature enzymatic pathways with high potential in diagnostics and therapeutics.

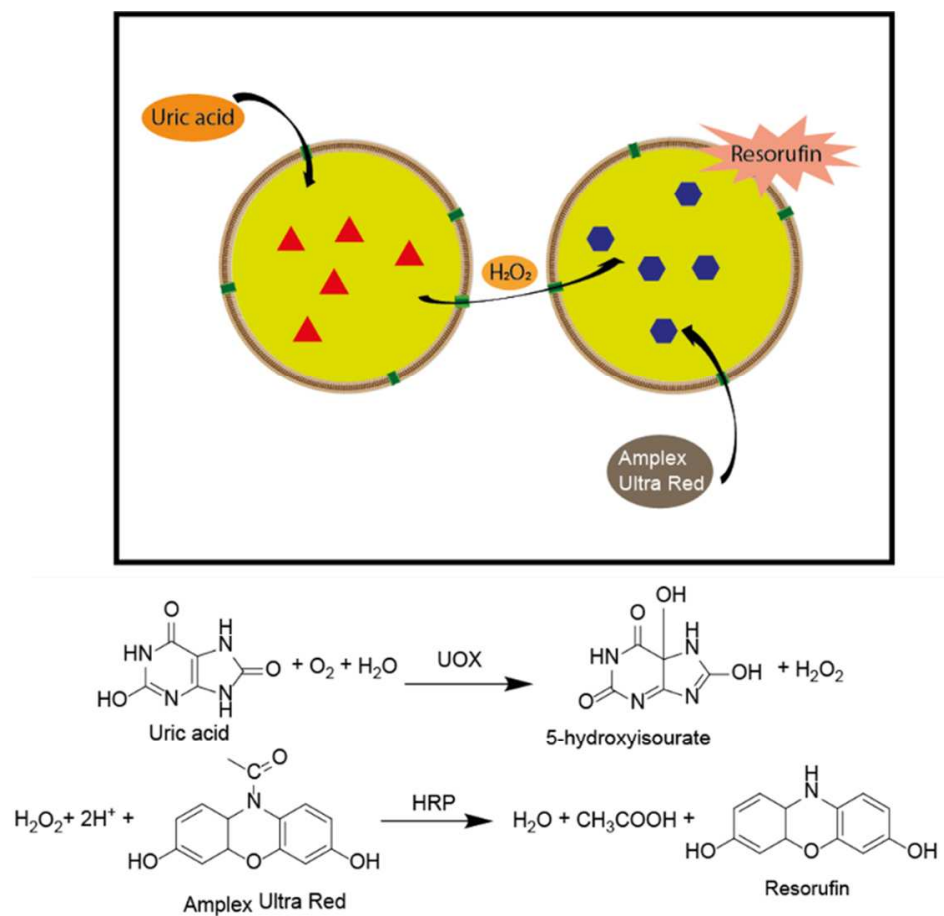

93 Scheme 1. Schematic representation of catalytic nanocompartments (OmpF: green rectangle) working in tandem and detailed

94 cascade reaction mediated by a combination of uricase (UOX, red triangles) and horseradish peroxidase (HRP, blue hexagons).

95 The oxidation of uric acid results in formation of 5-hydroxyisourate and hydrogen peroxide. The latter is a co-substrate for HRP

96 in presence of substrate Amplex Ultra Red, AR. The final product, resorufin, can be monitored by fluorescence spectroscopy.

\section{$98 \quad$ Materials}

99 Dulbecco's Modified Eagle Medium with $4.5 \mathrm{~g} \mathrm{~L}^{-1}$ D-Glucose (DMEM-GlutaMax) was 100 purchased from Gibco life technologies. Fetal calf serum (FCS) was purchased from 101 BioConcept. CellTiter 96® Aqueous One Solution Cell Proliferation Assay (MTS) was 102 purchased from Promega. The triblock copolymer $\mathrm{PMOXA}_{6}-\mathrm{PDMS}_{44}-\mathrm{PMOXA}_{6}$ was kindly 
103 provided by Prof. W. Meier, the University of Basel. ${ }^{23}$ All other reagents and enzymes were

104 purchased from Sigma-Aldrich unless otherwise specified.

\section{Methods}

106 OmpF expression and extraction

107 Wild-type OmpF was obtained according to a previously reported protocol, ${ }^{28}$ with a few 108 modifications: bacteria was grown at $30{ }^{\circ} \mathrm{C}$ for 6 hours on Terrific Broth (TB) (Difco, USA) and 109 all ultracentrifugations were performed at room temperature (RT).

110 Preparation of catalytic nanocompartments

111 All CNCs were prepared at RT using the triblock copolymer PMOXA $_{6}-\mathrm{PDMS}_{44}-\mathrm{PMOXA}_{6}$ 112 (obtained according to a previously reported procedure ${ }^{23}$ ) and wild-type OmpF, via the film 113 rehydration technique. Films were rehydrated to a final polymer concentration of $4 \mathrm{mg} \mathrm{mL}^{-1}$ with $1140.25 \mathrm{mg}$ of UOX or HRP in PBS ( $\mathrm{pH} 7)$ and $50 \mu \mathrm{l}$ of previously dialyzed OmpF $\left(60 \mu \mathrm{g} \mathrm{mL}^{-1}\right.$ 115 final concentration) or an equivalent volume of dialyzed octyl glucopyranoside, OG (Anatrace, 116 USA) $3 \%$ for the non-permeabilized CNCs. Samples were extruded through an Avanti mini117 extruder (Avanti Polar Lipids, USA) with a $200 \mathrm{~nm}$ pore diameter polycarbonate membrane (11 118 times). Non-encapsulated enzyme was removed through size exclusion chromatography (SEC) 119 (Sepharose 4B column; $30 \mathrm{~cm}$ length).

121 Catalytic nanocompartment characterization - Static and Dynamic light scattering

122 Light scattering (LS) experiments were performed at $25^{\circ} \mathrm{C}$, using an ALV/CGS-8F goniometer 123 (Langen/Hessen, Germany) equipped with a frequency-doubled He-Ne laser (LS instruments, $\lambda$ 
$124=633$ ). Static light scattering (SLS) was performed in $5^{\circ}$ steps between $50^{\circ}$ and $135^{\circ}$ and 125 analyzed with Zimm plot software (LS Instruments). Dynamic light scattering (DLS) was 126 performed at $90^{\circ}$ and analyzed through nonlinear decay-time analysis supported by cumulant fit. 127

128 Catalytic nanocompartment characterization - Transmission electron microscopy (TEM)

129 CNC suspensions in PBS at $0.25 \mathrm{mg} \mathrm{mL}^{-1}$ were deposited on glow-discharged carbon grids 130 (Quantifoil, Germany) stained with 1.5\% uranyl acetate solution and deposited on carbon-coated 131 copper grids. A transmission electron microscope (Philips Morgagni 268D) at $293 \mathrm{~K}$ was used.

133 Catalytic nanocompartment characterization - Fluorescence correlation spectroscopy

134 Vesicles were labeled with BODIPY 630/650 SE (Thermo Fisher Scientific, USA) $100 \mathrm{nM}$.

135 All measurements were carried out using an LSM 880 confocal laser microscope (Carl Zeiss, 136 Germany) with a 40x, 1.2 water immersion C-Apochromat objective lens. Measurements were 137 performed at RT using a sample volume of $20 \mu \mathrm{L}$ on a $22 \times 50 \mathrm{~mm}$ glass slide. A HeNe laser at $138633 \mathrm{~nm}$ was used for excitation of the BODIPY fluorophore, at $1 \%$ attenuation and pinhole 62 $139 \mu \mathrm{m}$. The fluorescence signal was measured in real time and the autocorrelation function was 140 calculated by the software calculator QuickFit 3.0. ${ }^{29}$ Measurements were recorded over $5 \mathrm{~s}$ and 141 each measurement was repeated 30 times. Experimental auto correlation curves were fitted using 142 a two-component model including triplet state:

$$
G(\tau)=1+\left(1+\frac{T}{1-T} e^{-\frac{\tau}{\tau_{\text {trip }}}}\right) \frac{1}{N}\left(\frac{f_{1}}{1+\frac{\tau}{\tau_{D 1}} \sqrt{1+R^{2} \frac{\tau}{\tau_{D 1}}}}+\frac{f_{2}}{1+\frac{\tau}{\tau_{D 2}} \sqrt{1+R^{2} \frac{\tau}{\tau_{D 2}}}}\right)
$$

$143 f_{1}$ and $f_{2}$ are respectively the fraction of the particles of the corresponding component 1 (dye) or 2 144 (vesicles), $\tau_{\mathrm{D} 1}$ represents the diffusion time of the dye and $\tau_{\mathrm{D} 2}$ the diffusion time of the vesicles, $\mathrm{T}$ 
145 the fraction of fluorophores in triplet state with triplet time $\tau_{\text {trip }}, \mathrm{N}$ is the number of particles and

$146 \mathrm{R}$ the structural parameter, fixed at 5, according to the guidelines from Zeiss. The $\tau_{\text {trip }}$ and $\tau_{\mathrm{D}}$ of

147 free dye were determined independently, and subsequently fixed in the fitting procedure for dye-

148 interacting vesicles. The confocal volume of $1 \mathrm{fL}$, was obtained by a calibration with free

149 BODIPY and was necessary to determine the concentration of fluorescent particles (knowing the 150 number of particles detected in the volume).

\section{Enzyme quantification}

153 The non-encapsulated enzyme fraction was recovered via SEC and the enhanced Pierce ${ }^{\mathrm{TM}}$ 154 Bicinchonic Acid (BCA) assay was performed according to the supplier's protocol (Thermo 155 Fisher Scientific, USA); instead of the BSA standards, both UOX (35 $\left.\mathrm{U} \mathrm{mg}^{-1}\right)$ and HRP (300 U $156 \mathrm{mg}^{-1}$ ) calibration curves were prepared for the quantification of the respective samples. The 157 amount of un-encapsulated protein was multiplied by the volume recovered from the column and 158 then subtracted from the amount initially added to the rehydration solution, yielding the total 159 amount of enzymes within the vesicles, divided by the volume of the vesicle (first fraction), i.e.

160 the final concentration of the protein. This was performed on samples with no inserted OmpF, 161 because the presence of the hydrophobic porin is not expected to influence the encapsulation 162 efficiency of hydrophilic enzymes. The number of enzyme molecules was then divided by the 163 number of vesicles, obtaining the number of enzymes per vesicle.

165 Enzyme activity and kinetics

166 Kinetic parameters were calculated using the Michaelis-Menten model:

$$
v=\frac{V_{\max }[S]_{0}}{K_{M}+[S]_{0}}
$$




$$
k_{\text {cat }}=\frac{V_{\max }}{[E]_{0}}
$$

167 Where $\mathrm{v}$ is the velocity of the enzyme, $\mathrm{V}_{\max }$ is the maximum velocity at saturating concentration,

$168[\mathrm{~S}]_{0}$ is initial the concentration of the substrate $\mathrm{S}, \mathrm{K}_{\mathrm{M}}$ is the Michaelis-Menten constant. $\mathrm{k}_{\mathrm{cat}}$ is the 169 turnover number, the number of chemical conversions per second, $[\mathrm{E}]_{0}$ is the concentration of 170 catalytic sites (both for UOX and HRP it is equivalent with the concentration of enzyme).

171 In all experiments involving a cascade reaction, UOX was added in excess to HRP, to partially 172 compensate for the former enzyme's lower activity, so that the ratio between production (from $173 \mathrm{UOX}, 35 \mathrm{U} \mathrm{mg}^{-1}$ ) and consumption (from HRP, $350 \mathrm{U} \mathrm{mg}^{-1}$ ) of hydrogen peroxide would not be 174 the limiting factor. All enzymatic measurements were performed using a Spectramax M5 175 microplate reader (Molecular Devices, USA), in a in a 96-well, flat bottomed UV-transparent 176 plate (Corning, USA) for uric acid absorbance $(290 \mathrm{~nm})$ or in a black plate (Thermo Fisher 177 Scientific) for resorufin fluorescence (excitation $570 \mathrm{~nm} /$ emission $595 \mathrm{~nm}$ ). The final volume in 178 each well was of $200 \mu \mathrm{L}$ in PBS. UOX concentration was increased ten-fold in cascade reaction 179 experiments, to counter the slower native activity per weight of the enzyme, compared to the 180 downstream enzyme HRP. Both uric acid consumption and resorufin production were quantified 181 by means of calibration curves $\left(\mathrm{R}^{2}>0.9\right.$ for both curves $)$. Each experiment was performed in 182 triplicate and data was collected over 15 minutes (10 for the measurement of kinetic parameters).

\section{UOX kinetics}

185 UOX or UOX-loaded CNCs (final concentration of $3 \mu \mathrm{g} \mathrm{mL} \mathrm{m}^{-1}$ ) were incubated in presence of 186 increasing concentrations of the substrate uric acid $(25,100,200,400$ and $800 \mu \mathrm{M})$ and the 187 initial velocity of the enzymatic reaction was determined. The consumption of uric acid was 
188 monitored and the data fitted with Graphpad Prism 7 software, obtaining $\mathrm{K}_{\mathrm{M}}, \mathrm{V}_{\max }$ and $\mathrm{k}_{\mathrm{cat}}$ 189 values.

190

191 HRP kinetics

192 HRP or HRP-loaded CNCs (final concentration of $3 \mu \mathrm{g} \mathrm{mL}^{-1}$ ) were incubated in the presence of $19310 \mu \mathrm{M} \mathrm{H}_{2} \mathrm{O}_{2}$ and increasing concentrations of Amplex Ultra Red (AR) (Invitrogen) ranging from 1940.2 to $20 \mu \mathrm{M}$. The initial velocity of the enzymatic reaction was determined by monitoring the 195 formation of resorufin. The data was fitted using Graphpad Prism 7 software, obtaining $\mathrm{K}_{\mathrm{M}}, \mathrm{V}_{\max }$ 196 and $\mathrm{k}_{\mathrm{cat}}$ values.

198 UOX-HRP cascade kinetics

199 Both reactions were examined when in a cascade: UOX or UOX-loaded CNCs (final 200 concentration of $3 \mu \mathrm{g} \mathrm{mL}^{-1}$ ) were added to HRP or HRP-loaded CNCs (final concentration 300 $201 \mathrm{ng} \mathrm{mL} \mathrm{m}^{-1}$ ) and both uric acid and AR were alternatively varied according to the previously listed 202 concentrations.

203

204 Amplex Ultra Red conversion assay in a cascade

205 The same cascade reaction was tested at different conditions: UOX or UOX-loaded CNCs (final 206 concentration of $3 \mu \mathrm{g} \mathrm{mL}^{-1}$ ) were added to HRP or HRP-loaded CNCs (final concentration 300 $207 \mathrm{ng} \mathrm{mL} \mathrm{m}^{-1}$ ), uric acid to a final concentration of $10 \mu \mathrm{M}$ and $\mathrm{AR}$ to a final concentration of $1 \mu \mathrm{M}$, 208 unless in controls where either substrate was missing and was substituted by the same volume of 209 PBS. The reaction profile in presence of catalase $\left(1000 \mathrm{U} \mathrm{mg}^{-1}\right.$, final concentration of $10 \mu \mathrm{g} \mathrm{mL}-$ 
$21{ }^{1}$ ) was blanked against the reaction profile of catalase alone in presence of AR, as catalase too 211 has a heme center capable of reacting with the fluorogenic molecule.

212

\section{Catalytic nanocompartment resilience to degrading agents}

214 Concentrations were $3 \mu \mathrm{g} \mathrm{mL}^{-1}$ for UOX or UOX-CNC and $300 \mathrm{ng} \mathrm{mL}{ }^{-1}$ for HRP or HRP-CNC. 215 For the heat resistance assay, aliquots of the polymersome were incubated at 37, 50, 60 and 75 $216{ }^{\circ} \mathrm{C}$ for either 10 or 30 minutes. For the chemical and enzymatic resistance assays, aliquots were 217 incubated with $6 \mathrm{M}$ guanidine hydrochloride $(\mathrm{GdnHCl})$ for 1 hour and $0.1 \mathrm{mg} \mathrm{ml}^{-1}$ Proteinase $\mathrm{K}$ 218 for 2 hours $\left(37{ }^{\circ} \mathrm{C}\right)$, respectively. Proteinase $\mathrm{K}$ was added in excess with respect to the other 219 enzymes (free and encapsulated). The production of resorufin was compared to that of the 220 cascade reaction with no additional elements and the ratio was calculated. To verify unspecific 221 binding, the same amount of enzyme (either UOX or HRP) was added to pre-formed empty 222 vesicles and then purified with the same protocol, then mixed with vesicles encapsulating the 223 other enzyme and the cascade kinetics were followed.

225 Activity of CNCs in serum

226 Activity in biological fluid was tested in human blood serum in which uric acid was dissolved to 227 a final concentration of $500 \mu \mathrm{M}$ at $37^{\circ} \mathrm{C}$, mimicking hyperuricemia. UOX or UOX-CNCs were 228 added to reach a final concentration of $18 \mu \mathrm{g} \mathrm{ml}^{-1}$, HRP or HRP-CNCs to $900 \mathrm{ng} \mathrm{ml}^{-1}$, AR to 10 $229 \mu \mathrm{M}$. The decrease of absorbance at $290 \mathrm{~nm}$ was monitored over the course of 6 hours. The 230 degradation of uric acid was defined as 


\section{Dependence of distance over reaction efficiency}

234 Knowing the amount of CNCs in a given volume (obtained from FCS measurements), it was 235 possible to calculate the mean inter-vesicle distance, assuming a cubic space occupied by the 236 compartments, as

$$
\frac{1}{\sqrt[3]{\frac{N}{V}}}
$$

237 where $\mathrm{N}$ is the number of particles (sum of UOX and HRP loaded-polymersomes) and V is the 238 reaction volume. A constant concentration of UOX-CNCs was mixed with a solution of HRP239 CNCs at concentrations: $2 \mathrm{x}, 1 \mathrm{x}, 0.5 \mathrm{x}, 0.25 \mathrm{x}, 0.1 \mathrm{x}, 0.02 \mathrm{x}, 0.01 \mathrm{x}$ and $0.005 \mathrm{x}$. The decrease in 240 concentration of HRP-CNCs induced an increase of the mean distance between polymersomes, 241 which was calculated using $\mathrm{N}=\mathrm{N}_{\mathrm{UOX}-\mathrm{CNC}}+\mathrm{N}_{\mathrm{HRP}-\mathrm{CNC} \text {. }}$ Resorufin production was monitored as 242 described above.

\section{Cell culture}

245 HEK293T cells were cultured in a humidified atmosphere with $5 \% \mathrm{CO}_{2}$ at $37{ }^{\circ} \mathrm{C}$ in Dulbecco's 246 Modified Eagle Medium with GlutaMAX ${ }^{\mathrm{TM}}$-I (4.5 $\mathrm{g} \mathrm{L}^{-1}$ D-Glucose, Gibco life technologies) and 247 supplemented with $10 \%$ Fetal calf serum (FCS, BioConcept), $100 \mathrm{U} \mathrm{mL}^{-1}$ penicillin and $100 \mu \mathrm{g}$ $248 \mathrm{~mL}^{-1}$ streptomycin (Sigma Aldrich).

250 Cell viability assay-MTS

251 For cell viability assessment, a CellTiter $96{ }^{\circledR}$ Aqueous One Solution Cell Proliferation Assay 252 (MTS, Promega) was used according to manufacturer instructions. Cells were seeded (5 000 253 cells/well in $100 \mu \mathrm{L}$ cell culture medium) in a 96-well plate and incubated for $24 \mathrm{~h}$. After $24 \mathrm{~h}$ 
254 the UOX-HRP-CNCs (concentrations ranging from 1.18 to $18 \mu \mathrm{g} \mathrm{mL}^{-1}$ of total polymer) were 255 diluted in PBS and added to the cells to reach a final volume of $200 \mu /$ well. After $24 \mathrm{~h}$ incubation 256 in presence of the CNCs, $20 \mu \mathrm{L}$ MTS reagent was added to each well. After $4 \mathrm{~h}$ absorbance was 257 measured at $490 \mathrm{~nm}$ using a Spectramax M5e plate reader. Background absorbance from control 258 wells containing all assay components without cells was subtracted from each well and data 259 normalized to control cells containing all components except CNCs.

261 Cell viability in presence of uric acid

262 Cells were seeded at a density of 5000 cells/well in $100 \mu \mathrm{L}$ cell culture medium, in a 96-well 263 plate and incubated for $24 \mathrm{~h}$. Next, cells were dosed with 250 or $500 \mu \mathrm{M}$ of uric acid, final 264 concentration, in the presence or absence of UOX-HRP-CNCs $\left(18 \mu \mathrm{g} \mathrm{mL}^{-1}\right.$ for UOX and $0.9 \mu \mathrm{g}$ $265 \mathrm{~mL}^{-1}$ for HRP, final concentrations in $200 \mu \mathrm{L}$ final volume) or in the presence of free enzymes 266 (UOX and HRP) at the same concentration. AR $(1 \mu \mathrm{M}$, final concentration in $200 \mu \mathrm{L}$ final 267 volume) was added to each well as a co-substrate for the HRP-CNCs. After a $24 \mathrm{~h}$ incubation 268 period, $20 \mu \mathrm{L}$ MTS reagent was added to each well. The absorbance was measured at $490 \mathrm{~nm}$ 269 after $4 \mathrm{~h}$. Background absorbance from control wells containing all assay components apart from 270 the cells was subtracted from each well and data normalized to control cells containing all 271 components except CNCs and uric acid.

272

273 Statistics

274 Multiple t-tests were performed using Graphpad Prism 7 software, comparing datasets, without 275 assuming constant standard deviation (SD). Statistical significance $(\mathrm{p}<0.05)$ was corrected using 
276 the Holm-Sidak method. Significance was marked as $* \mathrm{p}<0.05,{ }^{* *} \mathrm{p}<0.01, * * * \mathrm{p}<0.001$, 277 sample size was always $\mathrm{n}=3$.

278

279 Results and Discussion

280 Formation of UOX-Catalytic nanocompartments and HRP-Catalytic nanocompartments

281 We encapsulated UOX and HRP inside the supramolecular assemblies formed during the self282 assembly process of the copolymer by using film rehydration method due to its mild conditions, 283 which do not affect the biomolecules. ${ }^{70}$ The architecture of the supramolecular assemblies in 284 presence and absence of enzymes was established by a combination of LS and TEM. We used 285 SLS to obtain the radius of gyration $\mathrm{R}_{\mathrm{g}}$, and DLS for the hydrodynamic radius $\mathrm{R}_{\mathrm{h}}$. The ratio of 286 these values $R_{g} / R_{h}$, called $\rho$-factor, is indicative of the different architectures, e.g. 1 for hollow 287 spheres while 0.77 for solid spheres. ${ }^{31}$ In the case of empty supramolecular assemblies, $R_{g}$ and $288 \mathrm{R}_{\mathrm{h}}$ values were $70 \pm 33 \mathrm{~nm}$ and $84 \pm 25 \mathrm{~nm}$ respectively, and the calculated $\rho$-factor of 0.96 289 indicates hollow sphere architecture, thus formation of polymersomes. In the presence of UOX 290 (UOX-CNC), we determined for the supramolecular assemblies an $\mathrm{R}_{\mathrm{g}}$ of $68 \pm 12 \mathrm{~nm}$ and $\mathrm{R}_{\mathrm{h}}$ of $29173 \pm 33 \mathrm{~nm}(\rho=0.95)$, while in the presence of HRP (HRP-CNC) they had an $\mathrm{R}_{\mathrm{g}}$ of $74 \pm 35 \mathrm{~nm}$ 292 and $R_{h} 85 \pm 41 \mathrm{~nm}(\rho=0.87)$ (Figure S1). In both cases, the enzymes did not affect the self293 assembly process and resulted in polymersome architecture, which agrees with the TEM 294 micrographs (Figure 1A and 1C, Figure S2 and S3).

295 In order to quantify the amount of encapsulated enzymes inside the nanocompartments, we used 296 a combination of brightness measurements in FCS and BCA. FCS measures the fluorescence 297 fluctuations due to the Brownian motion of fluorescent species in a fL-sized volume, yielding 298 molecular parameters such as diffusion time and the number of particles that can be used to 
299 evaluate interactions/encapsulation of the fluorescent dyes with/in supramolecular assemblies. ${ }^{32}$ 300 By labeling the vesicle membrane with BODIPY 630/650, and using a 2-component fit (fixing 301 the diffusion time of free dye as one of the components) we obtained their average diffusion time $302\left(\tau_{\mathrm{D}} 5000 \mu \mathrm{s}\right.$ for both CNCs, as compared to $\tau_{\mathrm{D}}=57 \mu \mathrm{s}$ of the free dye) and overall number of 303 fluorescent vesicles in solution. The fraction of dye-polymersomes was $99 \%$ for UOX-CNCs and $30494 \%$ for HRP-CNCs $\left(2.6 \times 10^{11}\right.$ and $3.9 \times 10^{11}$ polymersomes $\mu \mathrm{L}^{-1}$, respectively), while that of the 305 free dye $1 \%$ and $4 \%$ thus indicating that most of the dye partitioned into the polymersome 306 membrane (Figure 1B and 1D).

307 A total protein concentration of $30 \mu \mathrm{g} \mathrm{mL}^{-1}$ for UOX and $18.6 \mu \mathrm{g} \mathrm{mL}^{-1}$ for HRP, was obtained 308 by BCA assay (Figure S4). Dividing the protein concentration by the number of polymersomes 309 obtained by brightness measurements, we determined an average of $11 \pm 7$ enzymes in UOX310 CNCs and $6 \pm 2$ enzymes in HRP-CNCs. An encapsulation efficiency of $36 \pm 12 \%$ for UOX and $31122 \pm 4 \%$ for HRP inside CNCs was obtained, in agreement with the encapsulation efficiency 312 values obtained for other enzymes inside polymersomes. ${ }^{7}{ }^{30}$ A number of 11 $313 \mathrm{OmpF} /$ polymersome was inserted as we used similar conditions as previously reported. ${ }^{33} \mathrm{We}$ 314 kept the amount of porin constant in order to distinguish the effect of all other molecular factors 315 on the cascade reaction. 
A

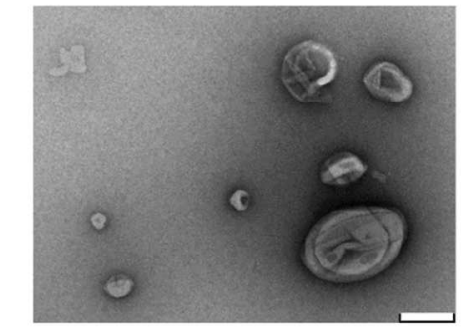

C

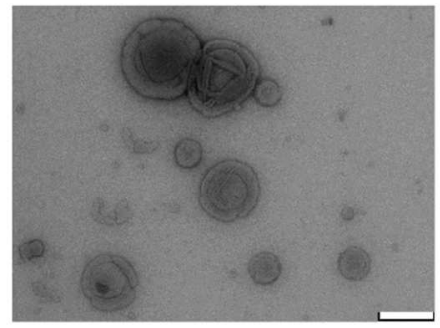

B

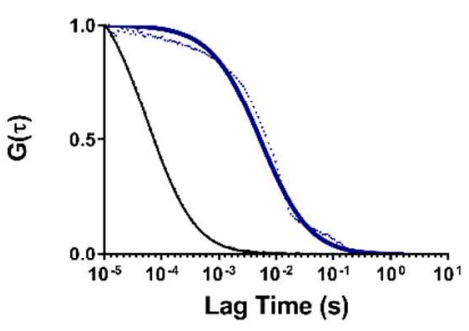

D

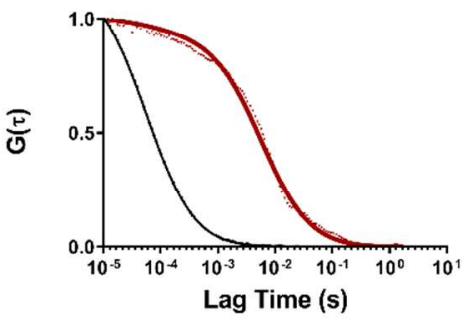

318 Figure 1. Formation of UOX-CNCs and HRP-CNCs. A: TEM micrograph of UOX-CNCs (scale bar: 200 nm). B: normalized

319 FCS autocorrelation curve of the dye labeled UOX-CNCs (dots: normalized raw data; solid line: fitted data, black line: free 320 BODIPY 630/650). C: TEM micrograph of HRP-CNCs (scale bar: $200 \mathrm{~nm}$ ). D: normalized FCS autocorrelation curve of the 321 dye-labeled HRP-CNCs (dots: normalized raw data; solid line: fitted data, black line: free BODIPY).

\section{Overall enzymatic efficiency of CNCs}

324 Having determined the amounts of encapsulated enzymes, we used the same concentrations in 325 bulk to evaluate the efficiency of the cascade reaction. The cascade reaction takes place when the 326 enzymes are free or encapsulated in separate nanocompartments equipped with OmpF (Figure 327 2A). The reaction cannot proceed when the membrane of the nanocompartments is not equipped 328 with OmpF, to allow molecular passage through (Figure 2B), or when one of the enzymes or 329 substrates is removed from the cascade (Figure 2C). 
2

3

4

5

6

7

8

9

10

11

12

13

14

15

16

17

18

19

20

21

22

23

24

25

26

27

28

29

30

31

32

33

34

35

36

37

38

39

40

41

42

43

44

45

46

47

48

49

50

51

52

53

54

55

56

57

58

59

60

A

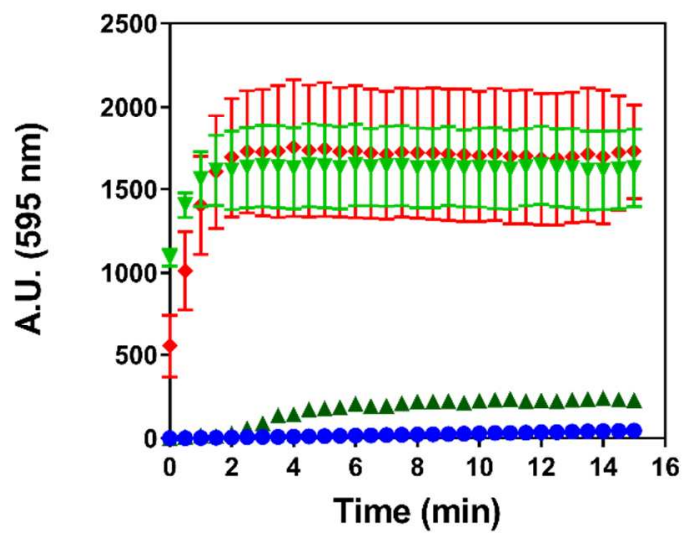

B

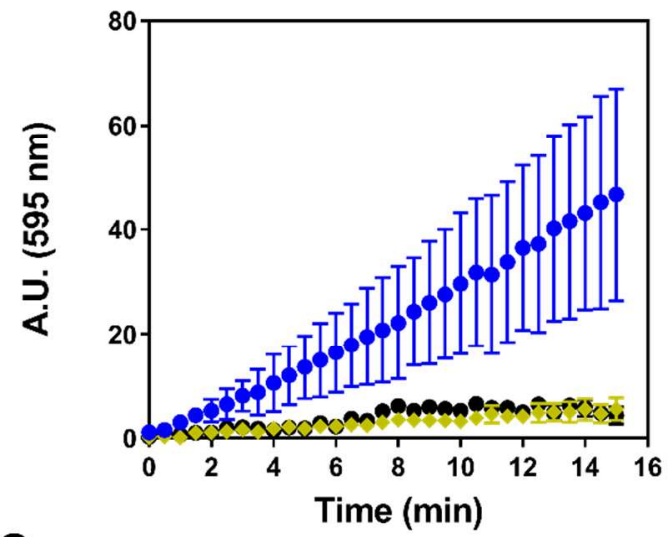

C

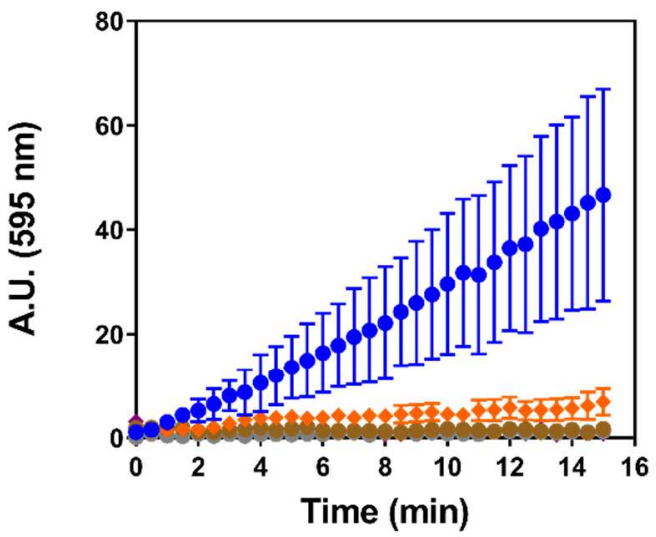

331 Figure 2. Cascade reaction with different setups. A: Enzyme kinetics when both enzymes are free (red), only HRP is free (light

332 green), only UOX is free (dark green) and both UOX and HRP are encapsulated inside polymersomes (blue). B: Cascade with 333 permeabilized CNCs (blue), unpermeabilized UOX-loaded polymersomes (olive), unpermeabilized HRP-loaded polymersomes 334 (black). C: Cascade reaction with both CNCs and the corresponding substrates (blue), and in the absence of one of the reaction 
compounds: HRP (orange), UOX (brown), AR (grey), and uric acid (purple). Error bars are given as mean $\pm S D(n=3)$, in some

cases bars are smaller than the corresponding dot.

338 As expected, the cascade reaction between separate nanocompartments is significantly slower 339 than that of the free enzymes. Going a step further, we were interested in establishing the effect 340 of the molecular diffusion through OmpF of substrates and products, examining the probability 341 that the product of the first reaction penetrates in a second CNC containing the HRP and 342 studying the effect of the distance between different CNCs on each step of the reaction and on its 343 overall efficiency. The conversion of AR to resorufin (AR conversion) was used as a comparison

344 standard, because it represents the last step of the cascade reaction and therefore accounts for 345 whether the whole cascade reaction takes place. First, we studied the influence of molecular 346 diffusion through $\mathrm{OmpF}$ as a key factor, which might limit the in situ enzymatic reaction inside 347 CNCs. Having one of the enzymes free in solution and the second one encapsulated in the CNCs, 348 AR conversion decreased compared with that of free enzymes. When HRP was surrounding 349 UOX-CNCs, a slight decrease in AR conversion to $92 \%$ was observed, while when UOX was 350 free around the HRP-CNCs, a significant decrease in AR conversion to $13 \%$ was obtained 351 (Figure 3). When both enzymes were encapsulated within the CNCs working in tandem, AR 352 conversion decreased significantly to $3 \%$ after 15 minutes. $\mathrm{As}_{2} \mathrm{O}_{2}$ is known to rapidly diffuse 353 through OmpF and it passes through the same barriers (membrane and inter-vesicle space) 354 regardless of which enzyme is inside the CNCs, its effect is only minor and is due to its 355 probability to interact with HRP. When only UOX is inside the CNCs, the slight decrease in AR 356 conversion is due to an inhomogeneous distribution of UOX-CNCs, which are the only source of $357 \mathrm{H}_{2} \mathrm{O}_{2}$. When HRP is inside the CNCs, the greater decrease in AR conversion is related to the 358 slow diffusion of AR through the OmpF pores, which is also the bottleneck for the cascade 
359 reaction between CNCs in tandem. Another factor that contributes to the significant decrease in

360 the reaction efficiency when CNCs are in tandem is the inhomogeneous CNC distribution which

361 reduces the probability that the substrates of the second reaction reach the HRP-CNCs. Besides,

362 the necessity of $\mathrm{H}_{2} \mathrm{O}_{2}$ transfer from UOX-CNCs to HRP-CNCs is proven by introducing free

363 catalase to the reaction mixture, as a competing enzyme that converts $\mathrm{H}_{2} \mathrm{O}_{2}$ to water and oxygen

364 (without Amplex Red as co-factor): when added, catalase strongly hinders the reaction mediated 365 by HRP (Figure S5A).

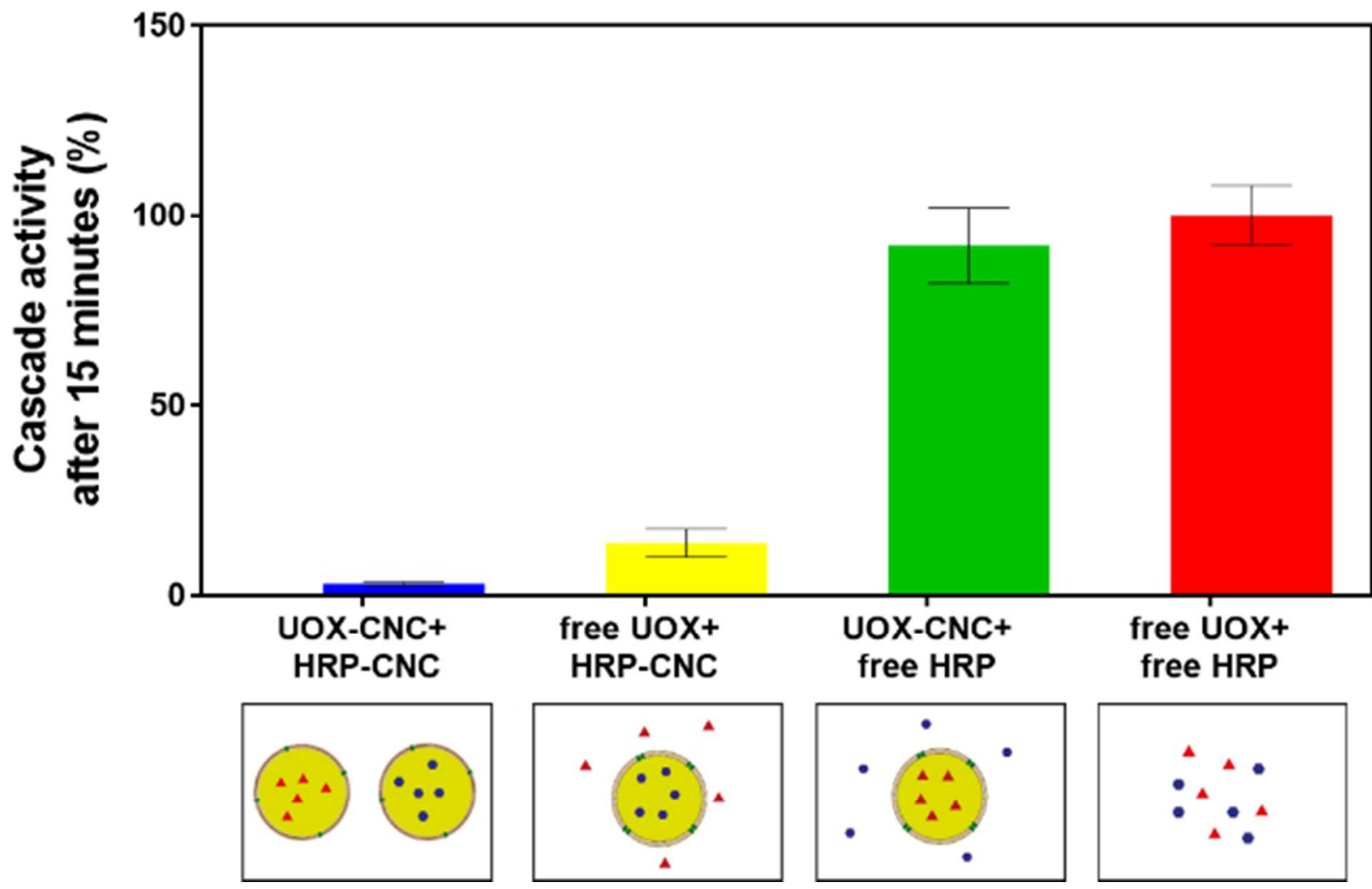

367 Figure 3. Conversion of AR to resorufin by a cascade enzymatic reaction when: both enzymes are encapsulated (blue), and only 368 HRP is encapsulated (HRP-CNCS) and UOX is free (yellow), only UOX is encapsulated (UOX-CNCS) and HRP is free (green), 369 both enzymes are free (red). Error bars are given as mean $\pm S D(n=3)$. 


\section{Kinetic analysis of $\mathrm{CNCS}$}

372 It is already known that encapsulation in polymersomes affects the kinetic parameters of

373 enzymes, by increasing their affinity for the substrates or decreasing the velocity, because they

374 are in a different environment than in solution. ${ }^{30}$ To characterize the behavior of CNCs, we first

375 compared the kinetic parameters of CNCs when isolated and then when acting in tandem by

376 using the Michaelis-Menten model (Table 1 and 2, Figure S6). Both steps of the cascade reaction

377 can be modeled in a first approximation by using Michaelis-Menten kinetics because in the first

378 reaction (UOX-CNCs) uric acid is added in excess, and for the second step both substrates are in

379 excess in the surroundings of the HRP-CNCs (AR added in excess in the medium, and $\mathrm{H}_{2} \mathrm{O}_{2}$

380 generated by UOX-CNCs with $\mathrm{V}_{\max }$ of $1.47 \times 10^{-3} \mu \mathrm{M} / \mathrm{min}$, which is one order of magnitude

381 higher than $\mathrm{V}_{\max }$ of HRP, as presented in Table 1 and 2).

$382 \mathrm{~K}_{\mathrm{M}}$, the Michaelis-Menten constant, defines the affinity of the enzyme for the substrate, and the 383 apparent $V_{\max }$ represents the maximal velocity at which the enzyme operates once it is saturated 384 by the substrate. As both $\mathrm{K}_{\mathrm{M}}$ and $\mathrm{V}_{\max }$ are intrinsic characteristics of the enzymes in specific 385 conditions, it is expected that these parameters are not affected by the enzyme encapsulation (if 386 the substrate/products diffusion is not changing due to possible barriers). However, we observe a 387 completely different situation: both $\mathrm{K}_{\mathrm{M}}$ and $\mathrm{V}_{\max }$ are affected by enzyme encapsulation (Table 1 388 and 2).

389 The apparent $\mathrm{K}_{\mathrm{M}}$ of both enzymes is lowered once confined in the nanocompartment, 4-times for 390 UOX-CNC and 1.5 times for HRP-CNC, which is in agreement with a previous publication 391 where encapsulated enzymes tend to exhibit a lowering in $\mathrm{K}_{\mathrm{M}}{ }^{34}$ However, this is not surprising 392 as the hollow cavity of a polymersome offers a more confined space, increasing the probability 393 of the substrate to access the catalytic center of the enzyme. ${ }^{30}$ In addition, there is a decrease in 
$394 \mathrm{~V}_{\max }$ and $\mathrm{k}_{\mathrm{cat}}$ values. The decrease of both $\mathrm{V}_{\max }$ and $\mathrm{k}_{\text {cat }}$ is significant in the case when UOX is 395 encapsulated in the CNCs (both for free HRP and for HRP-CNCs) (Table 1). On the contrary, 396 when HRP is encapsulated (free UOX and UOX-CNCs), the decrease in $\mathrm{V}_{\max }$ and $\mathrm{k}_{\text {cat }}$ values is 397 noticeably smaller (Table 2). We assume the change in $\mathrm{k}_{\text {cat }}$ values is associated with a slower 398 influx of the substrates to the enzyme's active site, a slower efflux of the products or a 399 combination thereof when the enzymes are inside the CNCs due to various barriers associated 400 with the polymersomes architecture. Similarly, $\mathrm{k}_{\mathrm{cat}} / \mathrm{K}_{\mathrm{M}}$ values decrease when the enzymes are 401 inside the CNCs. While the substrate can easily encounter the enzyme once inside the 402 compartment, the permeation through the membrane that is mediated by OmpF pores effectively 403 hinders the total activity of the cascade. The effect of diffusion to the enzyme is a well-known 404 parameter affecting and altering enzyme kinetics, as it can become the actual limiting factor in 405 their efficiency. ${ }^{35-36}$

Table 1. Apparent kinetic parameters for UOX: Michaelis-Menten constant $\left(K_{M}\right)$, maximal enzyme velocity $\left(V_{\max }\right)$, turnover rate $\left(k_{\text {cat }}\right)$ and catalytic efficiency $\left(k_{\text {cat }} K_{M}\right)$.

\begin{tabular}{|l|c|c|c|c|}
\hline & Free UOX & Free UOX in & UOX-CNC & UOX-CNC in \\
& & cascade & & \\
\hline $\mathrm{K}_{\mathrm{M}}(\mu \mathrm{M})$ & $3.70 \times 10^{2}$ & $3.68 \times 10^{2}$ & $8.32 \times 10^{1}$ & $9.09 \times 10^{1}$ \\
\hline $\mathrm{V}_{\max }(\mu \mathrm{M} / \mathrm{min})$ & $2.47 \times 10^{-1}$ & $2.77 \times 10^{-1}$ & $1.22 \times 10^{-4}$ & $1.47 \times 10^{-3}$ \\
\hline $\mathrm{k}_{\mathrm{cat}}(1 / \mathrm{s})$ & 2.72 & 2.55 & $1.34 \times 10^{-3}$ & $2.00 \times 10^{-3}$ \\
\hline $\mathrm{k}_{\mathrm{cat}} / \mathrm{K}_{\mathrm{M}}(1 /(\mu \mathrm{M} \mathrm{s}))$ & $7.30 \times 10^{-3}$ & $7.52 \times 10^{-3}$ & $1.60 \times 10^{-5}$ & $2.20 \times 10^{-5}$ \\
& & & & \\
\hline
\end{tabular}


Table 2. Apparent kinetic parameters for UOX: Michaelis-Menten constant $\left(K_{M}\right)$, maximal enzyme velocity $\left(V_{\max }\right)$, turnover rate $\left(k_{\text {cat }}\right)$ and catalytic efficiency $\left(k_{\text {cat }} K_{M}\right)$.

\begin{tabular}{|l|c|c|c|c|}
\hline & Free HRP & Free HRP in & HRP-CNC & HRP-CNC in \\
& & cascade & & \\
\hline $\mathrm{K}_{\mathrm{M}}(\mu \mathrm{M})$ & $3.50 \times 10$ & $3.0 \times 10$ & $2.22 \times 10$ & $1.92 \times 10$ \\
\hline $\mathrm{V}_{\max }(\mu \mathrm{M} / \mathrm{min})$ & $7.82 \times 10^{-4}$ & $8.19 \times 10^{-4}$ & $4.21 \times 10^{-5}$ & $1.32 \times 10^{-4}$ \\
\hline $\mathrm{k}_{\mathrm{cat}}(1 / \mathrm{s})$ & $1.14 \times 10^{-2}$ & $1.12 \times 10^{-2}$ & $1.94 \times 10^{-3}$ & $6.19 \times 10^{-3}$ \\
\hline $\mathrm{k}_{\mathrm{cat}} / \mathrm{K}_{\mathrm{M}}(1 / \mathrm{M} / \mathrm{s})$ & $4.10 \times 10^{-4}$ & $4 \times 10^{-4}$ & $2.80 \times 10^{-4}$ & $3.22 \times 10^{-4}$ \\
\hline
\end{tabular}

407

408 We exclude that the decrease in enzyme activity inside the CNCs is due to the confinement of 409 enzymes: encapsulated UOX (molecular radius $4.27 \mathrm{~nm}^{37}$ ) and HRP (molecular radius 2.98 $410 \mathrm{~nm}^{38}$ ) move free in a 1000-fold and 12000-fold greater volume inside the polymersome than their 411 intrinsic volume, respectively. We calculated the inner volume of polymersomes as the volume 412 of a sphere with a radius $\mathrm{R}=\mathrm{R}_{\mathrm{h}}-d$, where $d$ is the polymersome membrane thickness of 10.7 $413 \mathrm{~nm}$ (previously determined for $\mathrm{PMOXA}_{6}-\mathrm{PDMS}_{44}-\mathrm{PMOXA}_{6}$ compartments ${ }^{39}$ ).

\section{Role of compartmentalization on CNC activity}

415 In a similar manner as is the case for liposomes, the polymeric membrane of nanocompartments 416 is expected to offer protection of the encapsulated payload from external agents that would 417 degrade it, as for example proteolytic attack. ${ }^{40}$ We wanted to establish the protective role of the 
418 nanocompartments in the presence of physical factors such as high temperatures and different $\mathrm{pH}$ 419 values as well as degrading agents ( $\mathrm{GdnHCl}$ and Proteinase $\mathrm{K})$. We quantified the "activity 420 retention" as the ratio between the production of resorufin under standard conditions (RT, pH 7) 421 and in the presence of degrading conditions. Wild-type OmpF is known to be stable at relatively 422 extreme $\mathrm{pH},{ }^{41-43}$ resistant to proteolysis, ${ }^{44}$ chaotropic agents and temperatures up to $75{ }^{\circ} \mathrm{C} .{ }^{43}$

423 Therefore, the porin is neither affected by the mild conditions of the rehydration method used to 424 generate the catalytic compartments, nor by the presence of a more complex environment or 425 degrading agents, because it is also protected inside the compartments membrane.

426 While below $37^{\circ} \mathrm{C}$ both encapsulated and free enzymes preserve their activity, for higher 427 temperatures, a decrease in activity is observed, but to a significantly higher degree for the free 428 enzymes (Figure 4A, Figure S5D and S7). The ability of the polymeric membrane to protect the 429 encapsulated payload from the effect of higher temperatures ${ }^{45-46}$ which denatures the enzymes, 430 is essential for translational applications. The effect of $\mathrm{pH}$ was less straight forward, as these two 431 enzymes have a different $\mathrm{pH}$ optima: basic for UOX and acidic for HRP. ${ }^{47-48}$ While at $\mathrm{pH} 3$ there 432 is no apparent gain in activity from the enzyme encapsulation, at $\mathrm{pH} 9$ the $\mathrm{CNCs}$ are significantly 433 more active than the free enzymes acting in tandem (Figure 4B). The enzyme activity is further 434 affected upon encapsulation due to a complex scenario: i) the interplay between the lower 435 stability of HRP at higher $\mathrm{pH}$ values ${ }^{49}$ and the basic $\mathrm{pH}$ optimum of UOX, ii) the stabilization of 436 HRP - known to interact with hydrophobic substrates ${ }^{50}$ - once inside the compartment, and iii) an 437 increase in enzyme accessibility for the substrates due to the confined reaction space. ${ }^{30}$ Therefore 438 the effect of the $\mathrm{pH}$ on activity is less evident when the enzymes are free in solution and no 439 confinement effects are present. However, we chose a neutral $\mathrm{pH}$ to evaluate the CNCs in 440 tandem to be closer to physiological conditions, at which both enzymes are still active (Figure 
441 S5B), and where both the free enzymes and encapsulated ones have similar activity retention 442 values.

443 The addition of an enzyme denaturing chemical agent, such as $\mathrm{GdnHCl}$, decreased the enzyme 444 activity, which is significantly more pronounced when the enzymes are free. This clearly 445 indicates the protective role of compartmentalization (Figure 4C). The decrease in activity 446 retention values in the case of CNCs in tandem is mainly due to the diffusion of GdnHCl (95 Da) 447 through OmpF, which has a weight cut-off of $650 \mathrm{Da}^{51}$ Even though in a previous report $448 \mathrm{GdnHCl}$ diffused through the polymersome membrane, ${ }^{52}$ this is not observed here as shown by 449 the highly retained activity. The permeability of PMOXA-PDMS-PMOXA membranes varies 450 depending on the molecular factors, such as the thickness of the membrane, the polydispersity of 451 the copolymer chains or the conditions in which they are formed. In addition to the small number 452 of inserted OmpF that are enough to allow in situ enzymatic reaction, the innate resistance 453 towards denaturation of UOX ${ }^{53-54}$ and the possible stabilization of HRP due to interactions with 454 the membrane are responsible for maintaining enzymes' activity in the case of our CNCs, even in 455 presence of GdnHCl.

456 To mimic a proteolytic attack, we added Proteinase K both to free enzymes and the CNCs for 2 457 hours. While a significant decrease in activity retention was observed for the free enzymes (18 \pm $4581 \%)$, in the case of $\mathrm{CNCs}$ the decrease was considerably smaller $(83 \pm 3 \%)$, additionally showing 459 that a small fraction of enzyme molecules was adsorbed at the outer interface of the 460 polymersome $^{33}$ (Figure 4D). We considered the overall activity of the CNCs as a whole; 461 however, by adding free enzymes to empty vesicles and then purifying them, it was possible to 462 detect a certain amount of activity due to unspecific binding in the cascade for HRP, estimated to 
463 be around 3\% of the total (Figure S5C and Table S1). The auto-oxidation of AR was also taken 464 into account, and subtracted in all blanks.
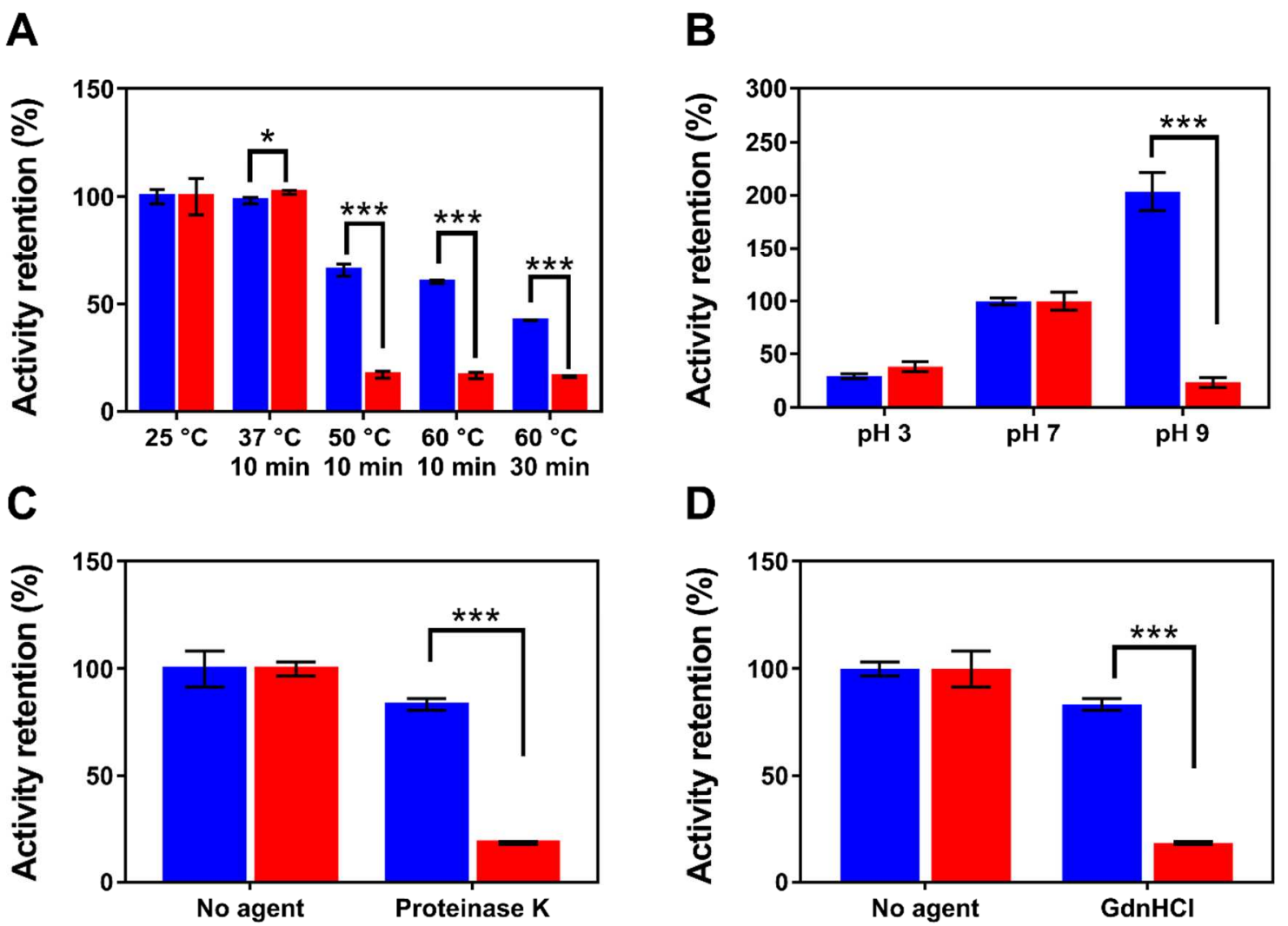

465

466 Figure 4. Stability of catalytic nanocompartments and free enzymes (activity normalized against CNCs (blue) or enzymes (red) at $467 R T$, neutral $p H$, no agents). A: protection from heat. B: protection from extreme pH. C: protection from denaturing agent 468 GdnHCl. D: protection from proteolysis. Error bars are given as mean $\pm S D$ (multiple $t-$ test, $* p<0.05, * * p<0.01, * * * p<$ $4690.001, n=3)$.

471 The effect of distance on the efficiency of the CNCs in tandem

472 The passage through barriers and diffusion between compartments represents an essential point 473 in bio-communication because products have, in some cases, to travel to different cellular 474 compartments or take part in inter-cellular communication. Most organelle-to-organelle 
475 communications in the cell happen via close association below $50 \mathrm{~nm}^{55}$ and the average synaptic 476 cleft is around $20 \mathrm{~nm},{ }^{56}$ whereas it is estimated that a single cell can effectively communicate 477 between 5 and $10 \mu \mathrm{m}$ in autocrine signaling and up to $250 \mu \mathrm{m}$ in paracrine signaling. ${ }^{57-58}$ In such 478 cases of communication between organelles or cells, there is no longer a homogeneous 479 distribution of enzymes or receptors but local high concentrations and otherwise empty or low 480 density interstices. We used our $\mathrm{CNCs}$ in tandem to mimic communication between bio481 assemblies and see the effect of distance on the overall cascade reaction efficiency. We assumed 482 a cubic volume for the compartments, so that the mean inter-compartment distance is calculated, 483 based on the polymersome density obtained by FCS.

484 The AR conversion values in the case of CNCs in tandem remains almost constant (with some 485 values higher than $100 \%$ as values fluctuate around the mean obtained at $0.8 \mu \mathrm{m}$, set as 486 reference) until the mean distance between $\mathrm{CNCs}$ is $1.3 \mu \mathrm{m}$, then the values decrease 487 significantly. This suggests that the diffusion of molecules through the OmpF pores represents 488 the dominant factor for distances lower than approximately $1.30 \mu \mathrm{m}$. Interestingly, the ratio 489 between the mean inter-compartment distance and their diameter is about 10, which has the same 490 order of magnitude as the ratio between a mean cell-cell communication distance for cells with a $4911 \mu \mathrm{m}$ diameter, such as bacteria. ${ }^{59}$ For distances between CNCs higher than $1.3 \mu \mathrm{m}$, the cascade 492 reaction is rapidly hindered due to a decrease in the probability that $\mathrm{H}_{2} \mathrm{O}_{2}$ encounters a HRP493 CNC (Figure 5). These distances are consistent with distances typical for autocrine signaling. 494 Therefore our findings, based on tandem CNCs in a simplified medium, represents a first 495 necessary step for better understanding cell communication. 


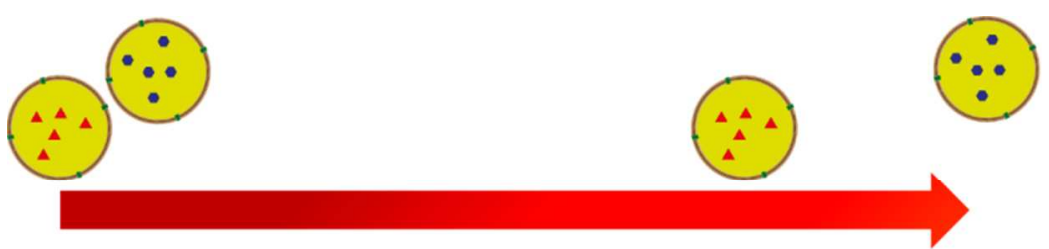

DECREASING CONCENTRATION

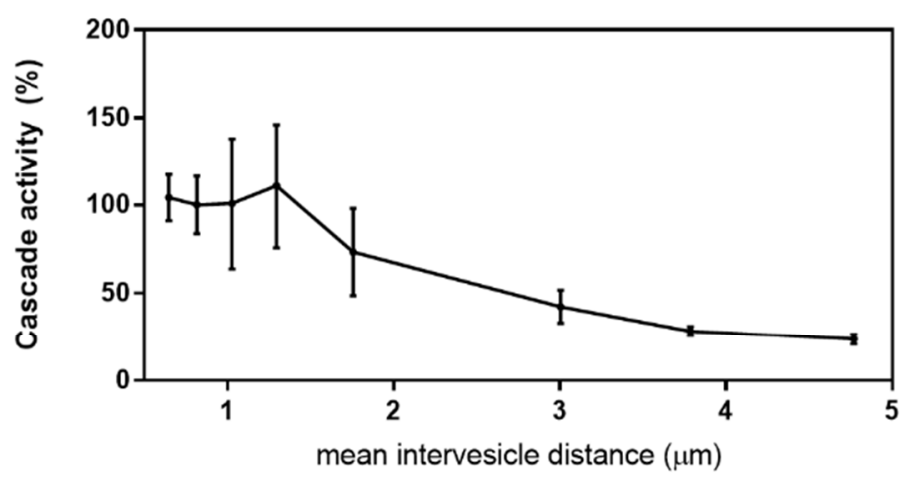

497 Figure 5. AR conversion by cascade reaction inside CNCs in tandem at different mean inter-vesicle distances. Error bars are 498 given as mean $\pm S D(n=3)$.

\section{CNCs in tandem in biologic conditions}

500 We then evaluated the functionality of the CNCs in biological conditions, both in biofluids and

501 upon incubation with cells, as more apropriate to advance translational applications. First, we 502 used human blood serum where uric acid was dissolved to reach levels similar to those 503 considered typical for hyperucemia $\left(>6.8 \mathrm{mg} \mathrm{dL}^{-1}\right.$ in $\left.\mathrm{men}^{60}\right)$. A simple model, defined as $504 \frac{\frac{\Delta A b s 290_{\text {with enzyme }}}{\text { min }}}{\frac{\Delta A b s 290_{\text {no }} \text { enzyme }}{\text { min }}}$ for the dilutions of HRP-CNCs, gives the relative efficiency of the cascade 505 reaction, which we called Relative Urate Degradation (R.U.D.) (Figure 6A). Interestingly, in 506 such a complex medium, CNCs facilitate the clearance of uric acid at a comparable rate to the 507 free enzyme. The addition of HRP removes $\mathrm{H}_{2} \mathrm{O}_{2}$, pulling the first reaction forward according to 508 Le Chatelier's principle. In addition, we observed no aggregation of polymersomes in serum, in 509 agreement with reported results on similar polymers. ${ }^{61}$ Note that only in PBS the free enzymes 
510 are better in terms of the cascade efficiency than when encapsulated inside polymersomes.

511 However, in serum, they perform similarly, which emphasizes the role of the compartments in 512 protecting the encapsulated enzymes in these conditions $\left(37^{\circ} \mathrm{C}, 6\right.$ hours), and support our 513 approach for further cell assessment. Further studies, beyond the scope of the present one, are 514 necessary to understand the bio-molecular factors affecting the efficiency of the overall cascade 515 reaction between $\mathrm{CNCs}$ in human serum.

516 Second, we determined the ability of the CNCs to metabolize uric acid and degrade $\mathrm{H}_{2} \mathrm{O}_{2}$ upon 517 incubation with cells, as an essential step towards medical applications. First, we evaluated the 518 cytotoxicity of CNCs when incubated with HEK293T cells overnight at different concentrations 519 of the CNCs (measured in polymer concentration) by MTS assay. CNCs have no cytotoxic effect 520 towards the cells, even at the highest polymer concentration $\left(0.19 \mu \mathrm{g} \mathrm{mL}^{-1}\right)$ (Figure 6B). Next, 521 CNCs were incubated with HEK293T epithelial cells for $24 \mathrm{~h}$ in the presence of increasing 522 amounts of uric acid $(250$ and $350 \mu \mathrm{M})$ : at physiological concentration and at the lower end of 523 hyperuricemia values. CNCs, known to be eventually internalized by cells, ${ }^{7}$ were added together 524 with uric acid because it accumulates extracellularly to toxic levels: in this manner CNCs 525 directly protect cells by degrading uric acid. Cell viability decreased to around $60 \%$ in the 526 presence of $250 \mu \mathrm{M}$ uric acid. By addition of either free enzymes or the CNCs, the cell viability 527 was unaffected by the presence of uric acid. Increasing the amount of uric acid to $350 \mu \mathrm{M}$ 528 reduces the viability of the cells to $2 \%$, while the cascade reaction of the free enzymes and of the 529 CNCs in tandem induce a protective effect against uric acid. In addition, due to the combination 530 of enzymes, $\mathrm{H}_{2} \mathrm{O}_{2}$ is also degraded as a result of the succesful cascade reaction process (Figure $5316 \mathrm{C}$ and $\mathrm{D})$. 
A

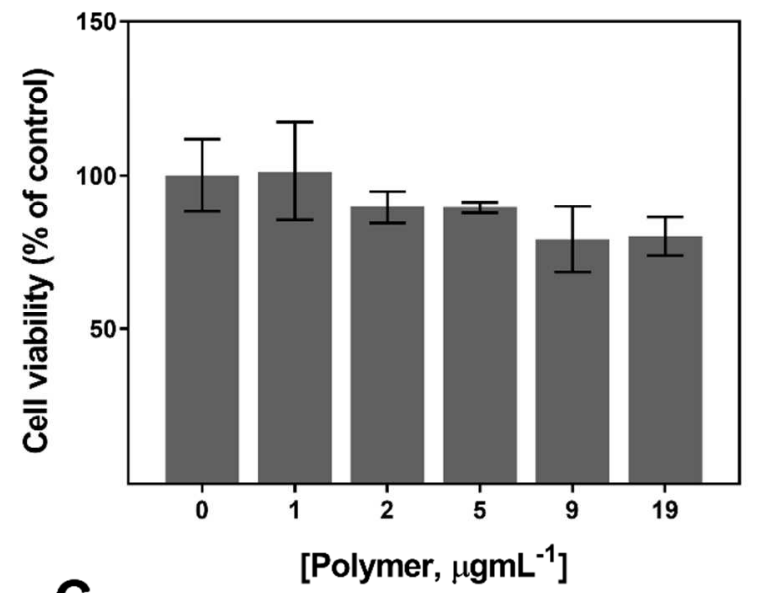

C

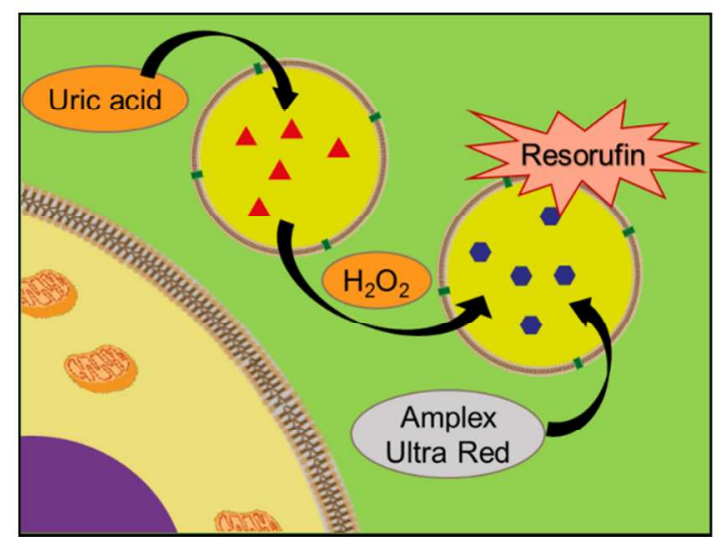

532

533

Figure 6. Activity of CNCs and free enzymes in blood serum and their interaction with cells. A: clearance of urate with both

534 CNCs (solid blue), UOX-CNC only (striped blue, no HRP-CNC), both free enzymes (solid red) and UOX only (striped red, no

535 HRP-CNC) B: cell viability of HEK293T cells incubated with CNCs at different concentrations (expressed as polymer

536 concentration). C: scheme of the CNC-cell interaction and detoxifying activity of the UOX-HRP cascade on cells only (green),

537 cells with free enzymes (blue) and cells with CNCs (red). Error bars are given as mean $\pm S D($ multiple $t-$ test, $* p<0.05, * * p<$ $5380.01, * * * p<0.001, n=3)$.

\section{Conclusions}

540 We designed two spatially segregated catalytic nanocompartments to support a cascade reaction

541 between them, mimicking sequential reactions between biosystems. By an elegant selection of 
542 the enzyme combination, we applied these catalytic nanocompartments in tandem to decrease

543 uric acid and $\mathrm{H}_{2} \mathrm{O}_{2}$, both involved in various pathologic conditions ranging from gout to

544 oxidative stress. A thorough analysis of the factors affecting the overall efficiency of the cascade

545 reaction between CNCs indicated the protective role of the compartments, which provide a shield

546 for the encapsulated enzymes, especially important in biological fluids and cellular environment.

547 For the first time, a kinetic evaluation of a cascade reaction between segregated reaction spaces

548 at the nanoscale has been achieved. We elucidated the limiting factors for the overall reaction: i)

549 the diffusion through the membrane pores inserted into the walls of the compartments and ii) the

550 probability of the products from the first reaction to encounter CNCs containing the second

551 enzyme and reach the encapsulated enzyme molecules. A balance is necessary between the

552 protective role of the nanocompartments and the factors that decrease the efficiency of the 553 cascade reaction for translational applications. This cascade reaction in separate compartments 554 has been successfully performed in serum and then used to decrease both uric acid and the 555 derived $\mathrm{H}_{2} \mathrm{O}_{2}$ from the cellular milieu as a first step towards medical applications. Our study is 556 the first one that proves that a two-compartment cascade reaction acts in cellular conditions, thus 557 contributing to the understanding of the design of complex catalytic compartments to cope with 558 biological requirements.

\section{Supporting Information}

561 Supporting information: additional physical characterization, enzymatic assays in various 562 conditions, Michaelis-Menten curves. (PDF)

\section{Corresponding Author}


564 Prof. Dr. Cornelia G. Palivan, Department of Chemistry, Physical Chemistry, Mattenstrasse 24a, 565 CH-4058 Basel

566 cornelia.Palivan@unibas.ch

\section{Author Contributions}

568 A.B contributed to the CNCs production and characterization, I.C contributed to the in vitro 569 assays, J.L. contributed to experiment design and enzymatic assays, and C.G.P contributed to the 570 concept of CNCs in tandem. The manuscript was written through contributions of all authors. 571 All authors have given approval to the final version of the manuscript.

\section{Acknowledgements}

573 We gratefully acknowledge the financial support provided by the Swiss National Science 574 Foundation, the University of Basel and the National Centre of Competence in Research 575 Molecular Systems Engineering. Authors thank Prof. Wolfgang Meier (University of Basel) for 576 providing the polymer, Dr. Samuel Lörcher for its synthesis and Gabriele Persy for the TEM 577 measurements. A.B. thanks Dr. Tomaž Einfalt (University of Basel) for the fruitful help and 578 discussions on handling of OmpF, and Prof. Lucio Isa (ETHZ), for his suggestion regarding the 579 distance mode. Authors thank Federica Rasa for the help with the illustrations.

\section{REFERENCES}

1. Kuchler, A.; Yoshimoto, M.; Luginbuhl, S.; Mavelli, F.; Walde, P., Enzymatic reactions 583 in confined environments. Nat Nanotechnol 2016, 11 (5), 409-20.

$584 \quad 2 . \quad$ Agapakis, C. M.; Boyle, P. M.; Silver, P. A., Natural strategies for the spatial 585 optimization of metabolism in synthetic biology. Nat Chem Biol 2012, 8 (6), 527-35.

586 3. Hosta-Rigau, L.; York-Duran, M. J.; Zhang, Y.; Goldie, K. N.; Stadler, B., Confined 587 multiple enzymatic (cascade) reactions within poly(dopamine)-based capsosomes. ACS Appl 588 Mater Interfaces 2014, 6 (15), 12771-9. 
589 4. Sakr, O. S.; Borchard, G., Encapsulation of Enzymes in Layer-by-Layer (LbL)

590 Structures: Latest Advances and Applications. Biomacromolecules 2013, 14 (7), 2117-2135.

591 5. Palivan, C. G.; Fischer-Onaca, O.; Delcea, M.; Itel, F.; Meier, W., Protein-polymer

592 nanoreactors for medical applications. Chem Soc Rev 2012, 41 (7), 2800-23.

593 6. Schoonen, L.; van Hest, J. C., Compartmentalization Approaches in Soft Matter Science:

594 From Nanoreactor Development to Organelle Mimics. Adv Mater 2016, 28 (6), 1109-28.

$5957 . \quad$ Tanner, P.; Onaca, O.; Balasubramanian, V.; Meier, W.; Palivan, C. G., Enzymatic

596 cascade reactions inside polymeric nanocontainers: a means to combat oxidative stress.

597 Chemistry 2011, 17 (16), 4552-60.

598 8. Blackman, L. D.; Varlas, S.; Arno, M. C.; Fayter, A.; Gibson, M. I.; O'Reilly, R. K.,

599 Permeable Protein-Loaded Polymersome Cascade Nanoreactors by Polymerization-Induced Self600 Assembly. ACS Macro Lett 2017, 6 (11), 1263-1267.

601 9. $\quad$ Peters, R. J.; Marguet, M.; Marais, S.; Fraaije, M. W.; van Hest, J. C.; Lecommandoux,

602 S., Cascade reactions in multicompartmentalized polymersomes. Angew Chem Int Ed Engl 2014, $60353(1), 146-50$.

604 10. Grafe, D.; Gaitzsch, J.; Appelhans, D.; Voit, B., Cross-linked polymersomes as 605 nanoreactors for controlled and stabilized single and cascade enzymatic reactions. Nanoscale 606 2014, $6(18), 10752-61$.

607 11. Taek, K. K.; M., C. J. J. L.; M., N. R. J.; M., v. H. J. C., A Polymersome Nanoreactor 608 with Controllable Permeability Induced by Stimuli-Responsive Block Copolymers. Advanced 609 Materials 2009, 21 (27), 2787-2791.

610 12. Schmitt, C.; Lippert, A. H.; Bonakdar, N.; Sandoghdar, V.; Voll, L. M., 611 Compartmentalization and Transport in Synthetic Vesicles. Front Bioeng Biotechnol 2016, 4, 19.

612 13. Lomora, M.; Garni, M.; Itel, F.; Tanner, P.; Spulber, M.; Palivan, C. G., Polymersomes

613 with engineered ion selective permeability as stimuli-responsive nanocompartments with 614 preserved architecture. Biomaterials 2015, 53 (0), 406-414.

615 14. van Oers, M. C.; Rutjes, F. P.; van Hest, J. C., Cascade reactions in nanoreactors. Curr 616 Opin Biotechnol 2014, 28, 10-6.

617 15. Bolinger, P. Y.; Stamou, D.; Vogel, H., An integrated self-assembled nanofluidic system 618 for controlled biological chemistries. Angew Chem Int Ed Engl 2008, 47 (30), 5544-9.

619 16. Brasch, M.; Putri, R. M.; de Ruiter, M. V.; Luque, D.; Koay, M. S.; Caston, J. R.; 620 Cornelissen, J. J., Assembling Enzymatic Cascade Pathways inside Virus-Based Nanocages 621 Using Dual-Tasking Nucleic Acid Tags. J Am Chem Soc 2017, 139 (4), 1512-1519.

622 17. Marguet, M.; Bonduelle, C.; Lecommandoux, S., Multicompartmentalized polymeric 623 systems: towards biomimetic cellular structure and function. Chem Soc Rev 2013, 42 (2), 512-29. 624 18. Godoy-Gallardo, M.; Labay, C.; Jansman, M. M. T.; Ek, P. K.; Hosta-Rigau, L., 625 Intracellular Microreactors as Artificial Organelles to Conduct Multiple Enzymatic Reactions 626 Simultaneously. Advanced Healthcare Materials 2016, 6 (4), 1601190.

627 19. Kuiper, S. M.; Nallani, M.; Vriezema, D. M.; Cornelissen, J. J.; van Hest, J. C.; Nolte, R. 628 J.; Rowan, A. E., Enzymes containing porous polymersomes as nano reaction vessels for cascade 629 reactions. Org Biomol Chem 2008, 6 (23), 4315-8.

630 20. Liu, X.; Formanek, P.; Voit, B.; Appelhans, D., Functional Cellular Mimics for the 631 Spatiotemporal Control of Multiple Enzymatic Cascade Reactions. Angewandte Chemie 632 International Edition 2017, 56 (51), 16233-16238. 
633 21. Wang, Z.; van Oers, M. C. M.; Rutjes, F. P. J. T.; van Hest, J. C. M., Polymersome 634 Colloidosomes for Enzyme Catalysis in a Biphasic System. Angewandte Chemie 2012, 124 (43), 635 10904-10908.

636 22. Wertheimer, A.; Morlock, R.; Becker, M. A., A revised estimate of the burden of illness 637 of gout. Current therapeutic research, clinical and experimental 2013, 75, 1-4.

638 23. Lörcher, S.; Meier, W., Cosolvent fractionation of PMOXA-b-PDMS-b-PMOXA: Bulk 639 separation of triblocks from multiblocks. European Polymer Journal 2017, 88, 575-585.

640 24. Nardin, C.; Thoeni, S.; Widmer, J.; Winterhalter, M.; Meier, W., Nanoreactors based on 641 (polymerized) ABA-triblock copolymer vesicles. Chemical Communications 2000, (15), 14336421434.

643 25. Azmi, N. E.; Ramli, N. I.; Abdullah, J.; Abdul Hamid, M. A.; Sidek, H.; Abd Rahman, 644 S.; Ariffin, N.; Yusof, N. A., A simple and sensitive fluorescence based biosensor for the 645 determination of uric acid using $\mathrm{H} 2 \mathrm{O} 2$-sensitive quantum dots/dual enzymes. Biosens 646 Bioelectron 2015, 67, 129-33.

647 26. Dai, M.; Huang, T.; Chao, L.; Xie, Q.; Tan, Y.; Chen, C.; Meng, W., Horseradish 648 peroxidase-catalyzed polymerization of L-DOPA for mono-/bi-enzyme immobilization and 649 amperometric biosensing of $\mathrm{H} 2 \mathrm{O} 2$ and uric acid. Talanta 2016, 149, 117-123.

650 27. Miland, E.; Miranda Ordieres, A. J.; Tunon Blanco, P.; Smyth, M. R.; Fagain, C. O., 651 Poly(o-aminophenol)-modified bienzyme carbon paste electrode for the detection of uric acid.

652 Talanta 1996, 43 (5), 785-96.

653 28. Einfalt, T.; Goers, R.; Dinu, I. A.; Najer, A.; Spulber, M.; Onaca-Fischer, O.; Palivan, C. 654 G., Stimuli-Triggered Activity of Nanoreactors by Biomimetic Engineering Polymer 655 Membranes. Nano Lett 2015, 15 (11), 7596-603.

656 29. JW. Krieger; Langowski, J. QuickFit 3.0: A data evaluation application for biophysics, 657 http://www.dkfz.de/Macromol/quickfit/, 2015.

658 30. Baumann, P.; Spulber, M.; Fischer, O.; Car, A.; Meier, W., Investigation of Horseradish 659 Peroxidase Kinetics in an "Organelle-Like" Environment. Small 2017, 13 (17).

660 31. Stauch, O.; Schubert, R., Structure of Artificial Cytoskeleton Containing Liposomes in 661 Aqueous Solution Studied by Static and Dynamic Light Scattering. Biomacromolecules 2002.

662 32. Habel, J.; Ogbonna, A.; Larsen, N.; Cherre, S.; Kynde, S.; Midtgaard, S. R.; Kinoshita, 663 K.; Krabbe, S.; Jensen, G. V.; Hansen, J. S.; Almdal, K.; Helix-Nielsen, C., Selecting analytical 664 tools for characterization of polymersomes in aqueous solution. RSC Advances 2015, 5 (97), $66579924-79946$.

666 33. Edlinger, C.; Einfalt, T.; Spulber, M.; Car, A.; Meier, W.; Palivan, C. G., Biomimetic 667 Strategy To Reversibly Trigger Functionality of Catalytic Nanocompartments by the Insertion of 668 pH-Responsive Biovalves. Nano Lett 2017, 17 (9), 5790-5798.

669 34. Chen, Q.; Schönherr, H.; Vancso, G. J., Block-Copolymer Vesicles as Nanoreactors for 670 Enzymatic Reactions. Small 2009, 5 (12), 1436-1445.

671 35. Bar-Even, A.; Noor, E.; Savir, Y.; Liebermeister, W.; Davidi, D.; Tawfik, D. S.; Milo, R., 672 The moderately efficient enzyme: evolutionary and physicochemical trends shaping enzyme 673 parameters. Biochemistry 2011, 50 (21), 4402-10.

674 36. Garcia-Viloca, M.; Gao, J.; Karplus, M.; Truhlar, D. G., How enzymes work: analysis by 675 modern rate theory and computer simulations. Science 2004, 303 (5655), 186-95.

676 37. Caliceti, P.; Schiavon, O.; Veronese, F. M., Biopharmaceutical properties of uricase 677 conjugated to neutral and amphiphilic polymers. Bioconjug Chem 1999, 10 (4), 638-46. 
678 38. Rennke, H. G.; Patel, Y.; Venkatachalam, M. A., Glomerular filtration of proteins: 679 clearance of anionic, neutral, and cationic horseradish peroxidase in the rat. Kidney Int 1978, 13 680 (4), 278-88.

681 39. Itel, F.; Chami, M.; Najer, A.; Lörcher, S.; Wu, D.; Dinu, I. A.; Meier, W., Molecular 682 Organization and Dynamics in Polymersome Membranes: A Lateral Diffusion Study.

683 Macromolecules 2014, 47 (21), 7588-7596.

684 40. Cao, X.; Chen, C.; Yu, H.; Wang, P., Horseradish peroxidase-encapsulated chitosan 685 nanoparticles for enzyme-prodrug cancer therapy. Biotechnology letters 2015, 37 (1), 81-8.

686 41. Ihle, S.; Onaca, O.; Rigler, P.; Hauer, B.; Rodríguez-Ropero, F.; Fioroni, M.; 687 Schwaneberg, U., Nanocompartments with a pH release system based on an engineered OmpF 688 channel protein. Soft Matter 2011, 7 (2), 532-539.

689 42. Nestorovich, E. M.; Rostovtseva, T. K.; Bezrukov, S. M., Residue Ionization and Ion 690 Transport through OmpF Channels. Biophysical Journal 2003, 85 (6), 3718-3729.

691 43. Phale, P. S.; Philippsen, A.; Kiefhaber, T.; Koebnik, R.; Phale, V. P.; Schirmer, T.; 692 Rosenbusch, J. P., Stability of trimeric OmpF porin: the contributions of the latching loop L2. 693 Biochemistry 1998, 37 (45), 15663-70.

694 44. Mukherjee, S.; Guptasarma, P., Direct proteolysis-based purification of an overexpressed 695 hyperthermophile protein from Escherichia coli lysate: a novel exploitation of the link between 696 structural stability and proteolytic resistance. Protein Expression and Purification 2005, 40 (1), 697 71-76.

698 45. Yan, M.; Ge, J.; Liu, Z.; Ouyang, P., Encapsulation of Single Enzyme in Nanogel with 699 Enhanced Biocatalytic Activity and Stability. Journal of the American Chemical Society 2006, $700 \quad 128(34), 11008-11009$.

701 46. Cecchin, D.; Battaglia, G. In Protein stabilisation by polymersome entrapment, 2016.

702 47. Critchlow, J. E.; Dunford, H. B., Studies on Horseradish Peroxidase The Journal of 703 Biological Chemistry 1972.

704 48. Mahler, H. R. a.; Baum, H. M. c.; Hübscher, G., Enzymatic oxidation of urate. Science 7051956.

706 49. Moosavi-Movahedi, A. A.; Nazari, K.; Saboury, A. A., Thermodynamics of denaturation 707 of horseradish peroxidase with sodium n-dodecyl sulphate and n-dodecyl trimethylammonium 708 bromide. Colloids and Surfaces B: Biointerfaces 1997, 9 (3), 123-130.

709 50. Di Risio, S.; Yan, N., Adsorption and inactivation behavior of horseradish peroxidase on 710 cellulosic fiber surfaces. J Colloid Interface Sci 2009, 338 (2), 410-419.

711 51. Saint, N.; Lou, K. L.; Widmer, C.; Luckey, M.; Schirmer, T.; Rosenbusch, J. P.,

712 Structural and functional characterization of OmpF porin mutants selected for larger pore size. II. 713 Functional characterization. J Biol Chem 1996, 271 (34), 20676-80.

714 52. Rosenkranz, T.; Katranidis , A.; Atta, D.; Gregor, I.; Enderlein, J.; Grzelakowski, M.;

715 Rigler, P.; Meier, W.; Fitter, J., Observing Proteins as Single Molecules Encapsulated in Surface716 Tethered Polymeric Nanocontainers. ChemBioChem 2009, 10 (4), 702-709.

717 53. Pitts, O. M.; Priest, D. G.; Fish, W. W., Uricase. Subunit composition and resistance to 718 denaturants. Biochemistry 1974, 13 (5), 888-92.

719 54. Pace, C. N.; Hermans, J., The Stability of Globular Protein. CRC Critical Reviews in 720 Biochemistry 1975, 3 (1), 1-43.

$721 \quad 55 . \quad$ Achleitner, G.; Gaigg, B.; Krasser, A.; Kainersdorfer, E.; Kohlwein, S. D.; Perktold, A.; 722 Zellnig, G.; Daum, G., Association between the endoplasmic reticulum and mitochondria of 
723 yeast facilitates interorganelle transport of phospholipids through membrane contact. Eur $J$ 724 Biochem 1999, 264 (2), 545-53.

725 56. Barberis, A.; Petrini, E. M.; Mozrzymas, J. W., Impact of synaptic neurotransmitter 726 concentration time course on the kinetics and pharmacological modulation of inhibitory synaptic 727 currents. Front Cell Neurosci 2011, 5, 6.

728 57. Francis, K.; Palsson, B. O., Effective intercellular communication distances are 729 determined by the relative time constants for cyto/chemokine secretion and diffusion. Proc Natl 730 Acad Sci U S A 1997, 94 (23), 12258-62.

731 58. Shvartsman, S. Y.; Wiley, H. S.; Deen, W. M.; Lauffenburger, D. A., Spatial range of autocrine signaling: modeling and computational analysis. Biophys $J$ 2001, 81 (4), 1854-67. 59. Chien, A. C.; Hill, N. S.; Levin, P. A., Cell size control in bacteria. Curr Biol 2012, 22 (9), R340-9. 60. Maiuolo, J.; Oppedisano, F.; Gratteri, S.; Muscoli, C.; Mollace, V., Regulation of uric acid metabolism and excretion. Int J Cardiol 2016, 213, 8-14. 61. Murdoch, C.; Reeves, K. J.; Hearnden, V.; Colley, H.; Massignani, M.; Canton, I.; Madsen, J.; Blanazs, A.; Armes, S. P.; Lewis, A. L.; Macneil, S.; Brown, N. J.; Thornhill, M. H.; Battaglia, G., Internalization and biodistribution of polymersomes into oral squamous cell 740 carcinoma cells in vitro and in vivo. Nanomedicine 2010, 5 (7), 1025-36.

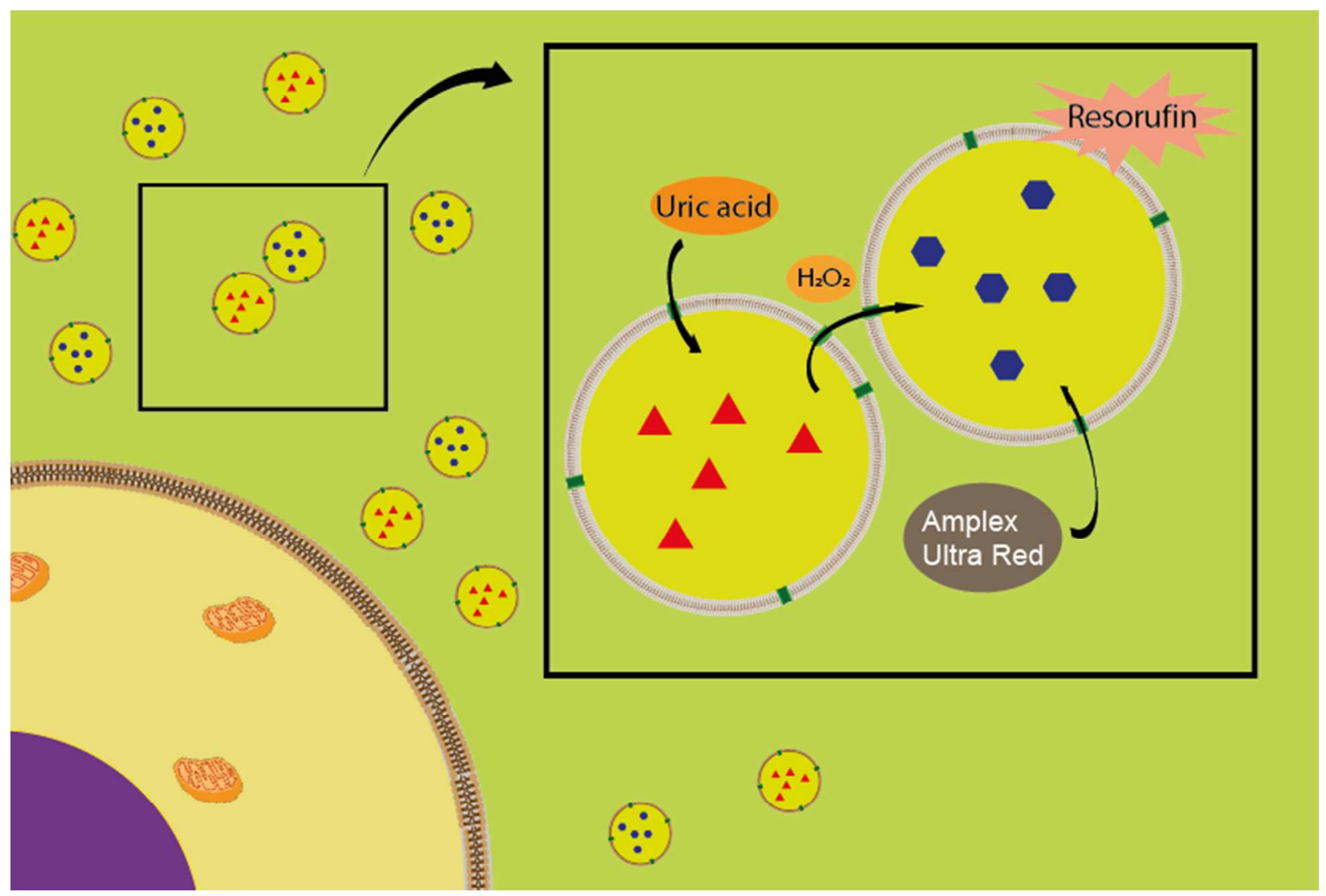

